\title{
PENGEMBANGAN MULTIMEDIA INTERAKTIF BERBASIS MASALAH UNTUK MENDAYAGUNAKAN KEMAMPUAN BERPIKIR TINGKAT TINGGI PADA SISWA SEKOLAH DASAR
}

\author{
Donna Avianty ${ }^{1}$, Dyah Ayu Sulistyaning Cipta ${ }^{2 *}$ \\ ${ }^{1,2}$ Pendidikan Matematika, IKIP budi Utomo Malang \\ E-mail: $\quad$ dav99.red@gmail.com ${ }^{1)}$ \\ dyahayu.esce@gmail.com ${ }^{2 *}$
}

Received 11 August 2018; Received in revised form 12 September 2018; Accepted 22 September 2018

\begin{abstract}
This research is intended to describe the learning design using interactive multimedia with the content in accordance with the 2013 curriculum which emphasizes character education and encourages students to utilize higher-order thinking skills. This interactive learning multimedia is based on problems. The research method used is a development research with an instructional design model, ADDIE. The instrument used in this study is problem solving and questionnaire tests. The results showed that problembased interactive multimedia designed to be able to utilize high-level thinking skills, as seen from the evaluation results of students with $86.2 \%$ completeness. The response process of students and teachers after the implementation of learning with interactive multimedia based on problems showed a very good response.
\end{abstract}

Keywords: high-level thinking skills; interactive multimedia; problem-based

\section{PENDAHULUAN}

Penerapan Kurikulum 2013 (K13) dalam proses pembelajaran pada setiap jenjang pendidikan diharapkan mampu mendorong siswa untuk dapat meningkatkan kemampuan berpikir intelektual ke arah kemampuan berpikir tingkat tinggi (High Order Thinking Skill-HOTS). K-13 dengan memberikan impulsdiharapkan agar siswa dapat berpikir secara kritis dalam menganalisa dan mengevaluasi sehingga dapat menciptakan pemecahan permasalahan yang ada.

Namun pada kenyataannya, penerapan K-13 sangat bervariatif. Ada beberapa sekolah yang mengupayakan pembelajaran berpusat pada siswa dan berusaha untuk menyempurnakan penerapan sesuai dengan tujuan K-13,

\footnotetext{
* Corresponding author. Address: Department of Mathematics Education, IKIP Budi Utomo, Malang, Indonesia

E-mail address: dyahayu.esce@gmail.com
}

namun tidak sedikit pula sekolahsekolah tetap menerapkan pembelajaran yang berfokus pada guru.

Padahal, menurut Kusnadi, dkk (2014), keberhasilan implementasi K-13 bergantung pada kreativitas guru yang merupakan faktor penting yang besar pengaruhnya, bahkan sangatmenentukan berhasil tidaknya peserta didik dalam belajar.

Pernyataan tersebut sangat berseberangan dengan kondisi beberapa sekolah yang guru lebih banyak mendominasi dalam proses pembelajaran dengan kegiatan penyampaian materi metode ceramah searah sehingga kegiatan belajar di kelas masih berfokus pada guru sebagai sumber utama informasi atau pengetahuan. Dalam kegiatan pembelajaran ini, siswa mencatat atau mengerjakan soal-soal di dalam lembar kerja. Siswa akan mengandalkan kemampuan mengerjakan dengan cara menghafal apa yang sudah disampaikan 
guru. Selain cenderung kurang menarik, pembelajaran seperti menghafal, memahami, dan menerapkan apa yang dihafal merupakan kemampuan berpikir tingkat rendah. Hal ini menjadi penghambat terwujudnya peningkatan kemampuan berpikir siswa dengan kualitas tinggi.

Seharusnya guru mengoptimalkan peranannya sebagai motivator yang mampu mendorong siswa untuk dapat belajar dengan baik sehingga kemampuan berpikirnya dapat meningkat. Guru sebagai fasilitator dapat menyediakan metode dan media pembelajaran yang mampu mengakomodir siswauntuk dapat belajar dengan mengasah penalaran, kemampuan analisis dan evaluasi. Dengan hal ini, makaakan dapat membentuk kreatifitas siswa untuk memiliki daya cipta yang tepat menjawab permasalahan yang ada.

Matematika juga merupakan salah satu alat untuk mengasah daya pikir siswa dalam pembelajaran. Namun di sisi lain objek matematika yang abstrak dan banyaknya pemaparan rumusrumus matematika untuk dihafal menjadikan matematika dianggap sulit dan kurang diminati oleh siswa, khususnya bagi siswa tingkat SD yang umumnya masih berada pada tahapan berpikir konkrit dengan fokus pada objek yang nyata atau pada berbagai kejadian yang pernah dialaminya. Pembelajaran matematika yang penyajiannya dalam bentuk permasalahan seharusnya dapat menjawab tantangan tersebut. Siswa SD diajak untuk menyelesaikan permasalahan nyata dalam kehidupan sehari-hari yang berhubungan dengan Matematika. Selain itu untuk menarik minat siswa dalam pembelajaran matematika digunakan multimedia yang interaktif sebagai media pembelajarannya.
Dengan demikian dibutuhkan pengadaan media pembelajaran yang menarik dan berbobot untuk diterapkan pada pembelajaran matematika SD. sehingga dapat menginspirasi dan menambah wawasan serta ketrampilan guru untuk dapat membantu siswa mendayagunakan kemampuan berpikir tingkat tinggi.

Melalui observasi sederhana yag dilakukan dengan wawancara kepada beberapa siswa SD Shining Star, SDN Ketawanggede I, dan SDI Mohammad Hatta, didapatkan bahwa masih jarang sekali guru mamanfaatkan fasilitas komputer sebagai media pembelajaran. Kondisi ini sangat disayangkan karena dengan kecanggihan teknologi seperti sekarang ini, seharusnya guru dapat memanfaatkan media komputer yang sudah dekat dengan kehidupan seharihari siswa. Sudah selayaknya komputer dapat digunakan sebagai media pembelajaran.

Posisi media pembelajaransebagai sumber belajar akan mulai menggeser fungsi guru terutama sebagai sumber belajar. Salah satu media yang dapat menjalankan fungsi demikian tersebut adalah program multimedia interaktif. Multimedia interaktif merupakan kumpulan dari beberapa media seperti tesk, gambar, audio, video, dan animasi yang bersifat interaktif yang digunkan untuk menyampaikan informasi (Nopriyanti dan Putu, 2015). Keunggulan multimedia interaktif, diantaranya dapat memberikan iklim afeksi secara individual, meningkatkan motivasi belajar, memberikan umpan balik, dan kontrol pemanfaatannya sepenuhnya berada pada penggunanya (Munadi, 2008).

Sesuai dengan tujuan penelitian ini, yaitu untuk mendayagunakan kemampuan berpikir tingkat tinggi siswa, maka pembelajaran dengan menggunakan multimedia interaktif 
pada penelitian ini mengacu pada pembelajaran berbasis masalah. Sunaryo (2014) mengungkapkan bahwa model pembelajaran berbasis masalah mampu meningkatkan kemampuan berpikir kritis dan kreatif siswa lebih baik dibandingkan model pembelajaran langsung. Dengan demikian, pembelajaran berdasarkan masalah merupakan pendekatan yang sangat efektif dalam proses berfikir tingkat tinggi. Pembelajaran ini membantu siswa untuk memproses informasi yang sudah jadi dalam benaknya dan menyusun pengetahuan mereka sendiri tentang dunia sosial dan sekitarnya. Pembelajaran berbasis masalah juga cocok untuk mengembangkan pengetahuan dasar maupun kompleks.

Melengkapi hal tersebut, Suprijono (2010:73) menyebutkan bahwa pembelajaran berbasis masalah terdiri dari lima fase dan perilaku. Fase 1: memberikan orientasi tentang permasalahannya kepada siswa, fase 2 : mengorganisasikan siswa untuk meneliti, fase 3: membantu investigasi mandiri dan kelompok, fase 4: mengembangkan dan mempresentasikan artefak dan exhibit, fase 5: menganalisis dan mengevaluasi proses mengatasi masalah.

Pada penelitian ini pembelajaran dimulai dengan menyajikan masalah nyata yang penyelesaiannya membutuhkan kerjasama antara siswa dan guru. Guru memandu siswa menguraikan rencana pemecahan masalah menjadi tahap-tahap kegiatan, guru memberi contoh mengenai penggunaan keterampilan dan strategi yang dibutuhkan supaya tugas-tugas tersebut dapat diselesaikan. Guru menciptakan suasana kelas yang fleksibel dan berorientasi pada upaya penyelidikan oleh siswa.

Selanjutnya, multimedia interaktif berbasis masalah ini diharapkan dapat menarik perhatian, minat maupun keterlibatan siswa dalam pembelajaran. Multimedia interaktif ini dipadukan dengan pembelajaran berbasis masalah dalam K-13 yang diharapkan dapat mendorong siswa untuk menggunakan penalarannya sehingga mengasah kemampuan berpikir tingkat tinggi pada siswa Sekolah Dasar.

\section{METODE PENELITIAN}

Penelitian ini merupakan penelitian pengembangan (research and development) yang diadaptasi dari Sugiyono (2012) yaitu model desain instruksional ADDIE yang meliputi tahap analisis (analysis), desain (design), pengembangan (develop), implementasi (implementation) dan evaluasi (evaluate) Pengembangan Multimedia Interaktif berbasis Masalah ini akan dilengkapi dengan langkahlangkah pembelajaran sesuai dengan Kurikulum 2013 dan soal dalam bentuk pemecahan permasalahan nyata, yang diharapkan dapat menstimulus pendayagunaan kemampuan berpikir tingkat tinggi pada siswa Sekolah Dasar.

Uji coba pengembangan Multimedia Interaktif Berbasis Masalah untuk Mendayagunakan Kemampuan Berpikir Tingkat Tinggi Siswa Sekolah Dasar ini dilaksanakan di SDN Ketawanggede I, SD Shining Star, dan SDI Mohammad Hatta yang terletak di Kota Malang. Penelitian dilaksanakan pada 23 Juli 2018 hingga 10 Agustus 2018 dengan subjek penelitian adalah guru dan siswa Kelas 4 pada ketiga sekolah tersebut. Siswa yang terlibat dalam penelitian iani sejumlah 29 Siswa SD Ketwanggede I, 27 Siswa SD Shining Star, dan 30 siswa SDI Mohammad Hatta.

Teknik pengumpulan data dilakukan dengan validasi produk multimedia interaktif yang telah dibuat 
kepada dua validator ahli media, aktivitas siswa dalam pembelajaran dengan menggunakan multimedia interaktif diamati sesuai dalam lembar observasi, identifikasi perubahan pendayagunaan kemampuan berpikir tinggi setelah penggunaan produk multimedia interaktif diamati berdasarkan hasil tes soal pemecahan masalah.

Respon siswa dan guru terhadap pembelajaran dengan menggunakan multimedia berbasis masalah dilakukan dengan pengambilan data berupa angket yang selanjutnya dilakukan analisis dengan perhitungan persentase respon sebagai berikut

$$
P R=\frac{\sum x i}{n} \times 100 \%
$$

$P R=$ persentase respon

$\sum x i=$ jumlah nilai jawaban responden $n=$ banyaknya data

Deskripsi rata-rata skor kriteria yang diperoleh dari hasil angket respon siswa dan guru disajikan dalam tabel kriteria penilaian respon siswa berikut:

Tabel 1. Kriteria Penilaian Respon Siswa

\begin{tabular}{cc}
\hline Persentase & Kriteria \\
\hline $0 \%<=\mathrm{PR}<=20 \%$ & Sangat buruk \\
$20 \%<\mathrm{PR}<=40 \%$ & Buruk \\
$40 \%<\mathrm{PR}<=60 \%$ & Cukup \\
$60 \%<\mathrm{PR}<=80 \%$ & Baik \\
$80 \%<\mathrm{PR}<=100 \%$ & Sangat Baik \\
\hline
\end{tabular}

\section{HASIL PENELITIAN DAN PEMBAHASAN}

Multimedia interaktif berbasis masalah untuk mendayagunakan kemampuan berpikir tingkat tinggi pada siswa sekolah dasar yang telah dirancang oleh peneliti menggunakan software PowerPoint yang dipadukan dengan visual basic. Pemilihan
PowerPoint ditujukan untuk mempermudah guru dalam menggunakan media ini sekaligus juga memudahkannya untuk pengembangan pada materi yang lain. Pada penelitian ini, multimedia interaktif yang telah dirancang adalah materi pecahan, disesuaikan dengan materi pelajaran yang sedang berlangsung di kelas IV pada saat pelaksanaan uji coba produk.

Sesuai dengan K-13 yang mengedepankan pendidikan karakter (Marlina, 2013), maka pada multimendia interaktif ini pun dimasukkan nilai-nilai pendidikan karakter, diantaranya adalah berdoa sebelum memulai pembelajaran (Gambar 1).

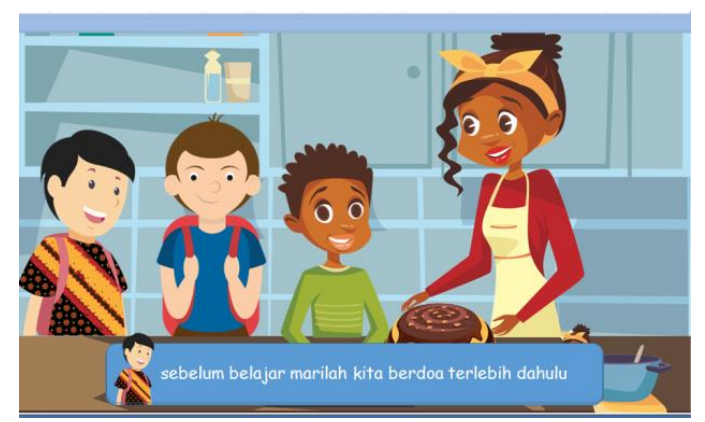

Gambar 1. Contoh penanaman pendidikan berkarakter

Multimedia interaktif berbasis masalah ini dimainkan oleh empat tokoh, yaitu ibu, Dido, Edward, dan Zaky (Tokoh seperti tertera pada Gambar 1). Permasalahan diawali dengan keinginan Dido untuk menikmati sendiri kue buatan ibu. Dengan memasukkan pendidikan karakter, ibu mengajarkan untuk berbagi, kue tersebut dibagi menjadi tiga bagian, dalam hal ini konsep pecahan digunakan.

Setelah diawali dengan konsep pecahan senilai, maka operasi pada pecahan dikenalkan berdasarkan konsep, sepeti yang tertera pada Gambar 2.

\section{$240 \mid$ AKSIOMA}




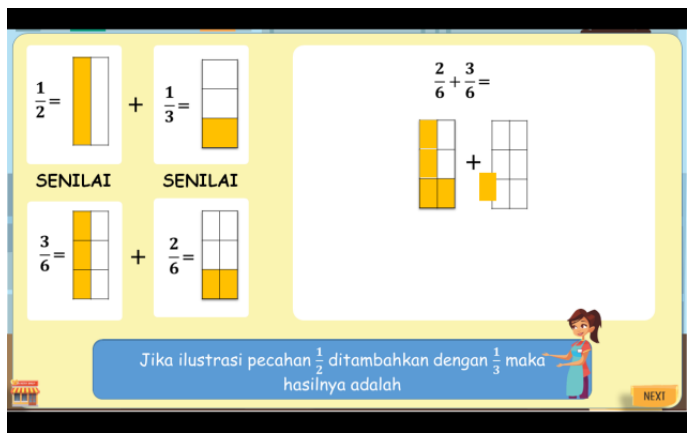

Gambar 2. Menghitung pecahan berdasarkan konsep

Pada multimedia pembelajaran interaktif ini, konsep pecahan benarbenar diberikan mengikuti logika siswa $\mathrm{SD}$, tidak serta merta diberikan rumus untuk menyamakan penyebut pada operasi penjumlahan dan pengurangan. Demikian pula halnya pada operasi perkalian dan pembagian, siswa tidak begitu saja diminta untuk mengalikan tanpa ia tahu mengapa demikian. Menurut Cipta (2018), mengerjakan pecahan dengan menghitung mengikuti algoritma tradisional sama halnya dengan melakukan perhitungan tanpa tahu apa arti dari perhitungan yang dilakukan.

Tidak terpaku pembelajaran searah, sesuai dengan namanya, multimedia interaktif ini melibatkan siswa untuk ikut dalam pembelajaran seperti yang tertera pada Gambar 3 berikut.

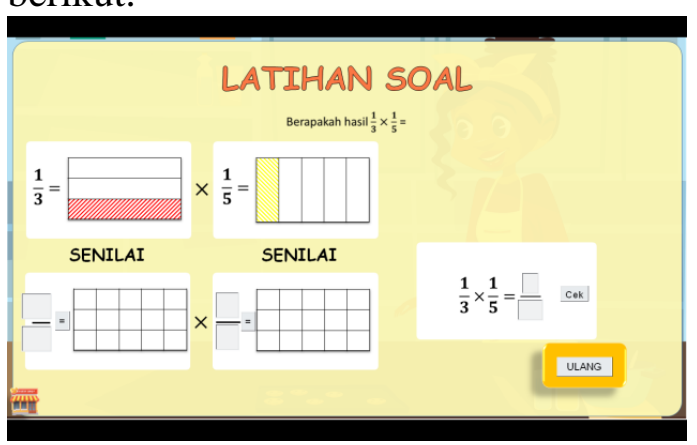

Gambar 3. Melibatkan siswa dalam pembelajaran

Saat siswa tidak dapat menjawab dengan benar pada, maka konsep operasi pecahan akan disajikan ulang.
Sebaliknya, jika siswa telah dapa mengerjakan dengan tepat, maka pembelajaran akan dilanjutkan pada pembahasan berikutnya.

Multimedia interaktif ini dilengkapi dengan evaluasi akhir yang terdiri dari 10 pertanyaan pilihan ganda yang disusun dengan berbasis masalah. Salah satu soal yang diberikan seperti yang tertera pada Gambar 4. Evaluasi berbentuk pilihan ganda dipilih karena multimedia interaktif ini juga disertai dengan penskoran yang dibuat dengan menggunakan bahasa pemrograman dalam visual basic. Namun demikian, siswa tetap diberikan kertas untuk menuliskan langkah-langkah yang dilakukan hingga mendapatkan jawabannya.

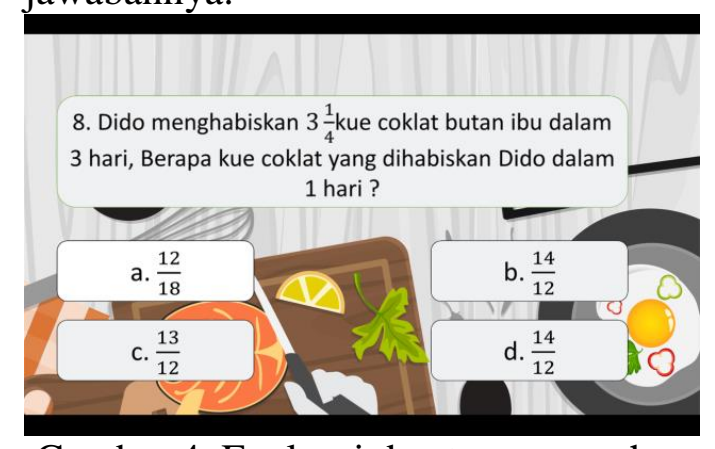

Gambar 4. Evaluasi dan tes pemecahan masalah

Multimedia interaktif yang telah divalidasi dan dinyatakan layak untuk diujicobakan, selanjutnya diberikan kepada guru untuk digunakan dalam proses pembelajaran di kelas 4. Dalam hal ini, peneliti ikut terjun langsung dalam proses pembelajaran.

Dari hasil identifikasi yang dilakukan terhadap evaluasi dengan memperhatikan langkah-langkah yang ditulis siswa dalam kertas, responden sejumlah 29 Siswa SD Ketwanggede I, 27 Siswa SD Shining Star, dan 30 siswa SDI Mohammad Hatta, didapatkan bahwa $86,2 \%$ dari mereka telah dapat mendayagunakan kemampuan berpikir tingkat tinggi. 
$\begin{array}{rrr}\text { Persentase } & \text { respon siswa dan } \\ \text { guru } & \text { dengan } & \text { diterapkannya }\end{array}$ pembelajaran multimedia interaktif berbasis masalah adalah $85 \%$ dan $82 \%$ dari SD Ketawanggede I, $74 \%$ dan $80 \%$ dari SD Shining Star, serta $81 \%$ dan $86 \%$ dari SDI Mohammad Hatta. Persentase tersebut menunjukkan bahwa respon siswa dan guru terhadap pembelajaran menggunakan multimedia interaktif berbasis masalah untuk mendayagunakan kemampuan berpikir tingkat tinggi sangat baik. Lebih ringkas, hasil persentase respon siswa dan guru tersebut disajikan dalam Gambar 5.

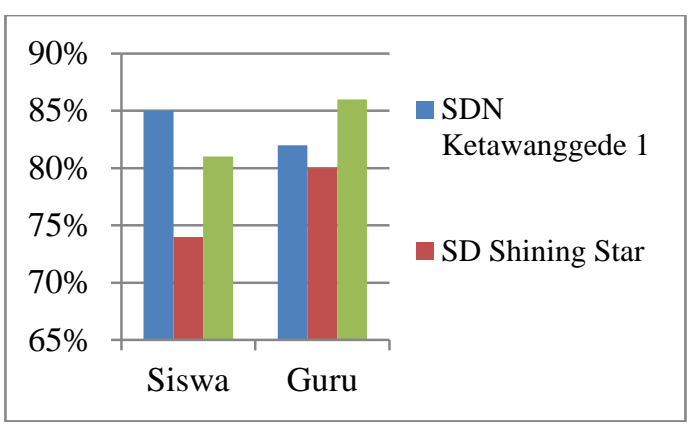

Gambar 5. Persentase Respon

\section{KESIMPULAN DAN SARAN}

Multimedia interaktif berbasis masalah tepat digunakan dalam K-13. Penanaman pendidikan berkarakter dapat dimasukkan pada desain multimedia interaktif dengan mengacu pada masalah dalam kehidupan seharihari. Pendayagunaan kemampuan berpikir tingkat tinggi siswa sekolah dasar dapat dipacu dengan desain soal berbasis masalah pada multimedia interaktif tersebut. Multimedia interaktif dapat dibuat dengan menggunakan power point agar lebih memudahkan guru untuk menggunakan maupun mengembangkannya, serta dilengkapi dengan pemrograman visual basic agar dapat melakukan penskoran.

Berikutnya, untuk mendapatkan hasil yang lebih maksimal, pembelajaran multimedia interaktif ini dapat dilengkapi dengan modul dan lember kerja siswa agar pembelajaran lebih terarah.

\section{DAFTAR PUSTAKA}

Cipta, D.A.S. (2018). Kupas Tuntas Konsep Bilangan dan Operasinya. Malang: Media Nusa Creative

Kusnadi, dkk. (2014). Implementasi Kurikulum 2013 dalam Pembelajaran Matematika di SMA Negeri 1 Makassar. Jurnal Matematika dan Pembelajaran, 2 (1): 123-135

Marlina, M. E. (2013). Kurikulum 2013 yang Berkarakter. JUPIIS, 5 (2): 27-38

Munadi, Y. (2008). Media Pembelajaran: Sebuah Pendekatan Baru. Jakarta: Gaung Persada Press Nopriyanti dan Putu. (2015). Pengembangan Multimedia Pembelajaran Interaktif Kompetensi Dasar Pemasangan Sistem Penerangan dan Wiring Kelistrikan di SMK. Jurnal Pendidikan Vokasi, 5 (2): 222-235 Sugiyono. (2012). Metode Penelitian Administrasi: Dilengkapi dengan

Metode $R \& D$. Bandung: Alfabeta

Sunaryo, Y. (2014). Model Pembelajaran Berbasis Masalah untuk Meningkatkan Kemampuan Berpikir Kritis dan Kreatif Matematik Siswa SMA di Kota Tasikmalaya. Jurnal Pendidikan dan Keguruan, 1 (2): 41-51

Suprijono. (2010). Cooperative Learning Teori dan Aplikasi PAIKEM. Yogyakarta: Pustaka Pelajar. 